\title{
Applied multi-pulsed laser in surface treatment and numerical-experimental analysis
}

\author{
Abdellah Laazizi ${ }^{a}$, Bruno Courant ${ }^{a}$, Frédéric Jacquemin ${ }^{a}$, Henri Andrzejewski ${ }^{b}$ \\ ${ }^{a}$ GeM, Institut de Recherche en Génie Civil et Mécanique, Université de Nantes-ECN, UMR CNRS 6183, IUT de Saint-Nazaire 37, Boulevard de l'Université, BP 406, \\ Saint-Nazaire 44602, France \\ ${ }^{\mathrm{b}}$ Institut Carnot de Bourgogne, UMR 5209 CNRS-Université de Bourgogne, IUT Le Creusot 12, rue de le Fonderie 71200 Le Creusot, France
}

\begin{abstract}
This paper presents a comparison between simulation and experimental results of the melting process of metallic material by a pulsed laser source NdYAG. The simulations of temperature and velocity fields of melted material were done by solving the transient heat transfer and fluid-flow equations. Variations of the thermophysical properties were considered. Furthermore, the model included the effects of the surface-tension gradient on the fluid surface and the buoyancy force. The simulation was useful in improving our understanding of the phenomena occurring in the treated material. Using a laser triangulation sensor, an experimental study was also conducted on the surface profile of the melted zones to seek a relationship between the socalled keyhole effect and the laser triangulation measurements. The keyhole effect induced strong surface deformations and often formed cavities, which were undesirable in the surface treatment process. The laser power, energy density, and treatment duration could be optimized to prevent the keyhole effect. The predicted laser melted zone (LMZ) morphology was in good agreement with the corresponding experimental measurements for various irradiation conditions, as long as the keyhole effect did not occur.
\end{abstract}

Keywords:

Pulsed laser irradiation Surface profile Numerical simulation

\section{Introduction}

The role of heat-transfer phenomena in welding and surface treatment is crucial for obtaining high quality surfaces by eliminating defects, such as undercutting, non-uniform surface profile, and cavities, which are attributed to changes in fluid flow and heat transfer [1].

Numerical and analytical models to simulate heat transfer and fluid flow during steady and transient fusion welding were developed during the last two decades. Calculations were obtained for both moving [2] and stationary heat sources and for laser beam as well as arc welding [3]. In an arc weld pool, flow driven by both surface tension and electromagnetic fields play an important role. However, in laser welding, only surface tensiondriven flow is significant [1]. These models were used to calculate weld pool geometry by calculating temperature fields during the welding of stainless steel [4], aluminum alloys [5], titanium alloys [6], and pure iron [7].

Pulsed lasers are used as the energy source for cutting, welding, rapid manufacturing, machining and ablation, melting, alloying [8], cladding, and surface hardening of the materials [9].
The understanding of the laser irradiation of materials involves numerous phenomena namely heat transfer, absorption, Marangoni convection, distortion, variation of the thermophysical properties, and phase transformation.

Until now, a model that considers all these phenomena has not existed because of the multidisciplinary nature of the problem spanning thermal, chemical, and mechanical fields. As a result, most researchers have concentrated on modeling only the melted zone without comparing simulation to experimental results. Moreover, the efficiency and the quality of the laser material processing depend on a large number of variables: the spatial and temporal energy distributions, the laser parameters, and the irradiated material properties.

Considerable research efforts were focused on exploring the laser processing of different materials. Treatment simulations were especially essential for processing control, minimizing the experimental cost, providing optimization of operative parameters, and improving understanding of Marangoni convection involved during the laser irradiation. Therefore, over the last two decades, several analytical $[6,10]$ and numerical models [11] were developed to predict the temperature and velocity fields in the melting bath during laser treatments. Numerical methods based on finite differences or finite elements were often used when the variations of material properties and/or convection flows in the molten bath were taken into consideration [12]. 


\begin{tabular}{|c|c|c|c|}
\hline \multicolumn{2}{|c|}{ Nomenclature } & $h$ & heat transfer coefficient, $80\left(\mathrm{~W} / \mathrm{m}^{2} \mathrm{~K}\right)$ \\
\hline$A_{p}$ & size of the laser beam & $k$ & thermal conductivity $(\mathrm{W} / \mathrm{m} \mathrm{K})$ \\
\hline$C_{p}$ & heat specific $(\mathrm{J} / \mathrm{kg} \mathrm{K})$ & $r_{b}$ & radius of laser beam, $200(\mu \mathrm{m})$ \\
\hline E & pulse energy $(\mathrm{J})$ & $t$ & time $(s)$ \\
\hline$H$ & enthalpy ( $\mathrm{J} / \mathrm{kg})$ & $x, z$ & Cartesian coordinates $(\mathrm{m})$ \\
\hline HAZ & heat-affected zone & & \\
\hline $\begin{array}{l}L_{m} \\
\text { LMZ }\end{array}$ & $\begin{array}{l}\text { latent heat of fusion, } 2.72 \times 10^{5}(\mathrm{~J} / \mathrm{kg}) \\
\text { laser-melted zone }\end{array}$ & \multicolumn{2}{|c|}{ Greek symbols } \\
\hline$L, Z$ & length and thickness of the workpiece & $\beta$ & thermal coefficient of volume expansion, $12.1 \times 10^{-6}$ \\
\hline NAZ & non-affected zone & & $\left(\mathrm{K}^{-1}\right)$ \\
\hline$P$ & pressure $(\mathrm{Pa})$ & $\sigma$ & tension surface \\
\hline$Q_{\text {laser }}$ & heat transfer flux from laser & $\mu$ & dynamic viscosity $\left(\mathrm{kg} / \mathrm{m} \mathrm{s}_{-}\right.$ \\
\hline$S$ & source-term & $\rho$ & density $\left(\mathrm{kg} / \mathrm{m}^{3}\right)$ \\
\hline$T$ & temperature $\left({ }^{\circ} \mathrm{C}\right)$ & $\delta$ & absorption coefficient \\
\hline$T_{0}$ & initial temperature, $23\left({ }^{\circ} \mathrm{C}\right)$ & $\tau$ & pulse duration (s) \\
\hline$T_{m}$ & melting point, $1535\left({ }^{\circ} \mathrm{C}\right)$ & & \\
\hline
\end{tabular}

Laser-material interactions are very complex, and only in the simplest cases, the laser can be treated as a simple surface heat source. The numerous effects of laser-material interactions were immediately the focus of physical research soon after an operational laser was built [4].

Computed temperature fields were used for predicting residual stress, while velocity fields could be used to determine the distribution of chemical elements in the transfer phenomena. Chan et al. [1] reported that the recirculating velocity, as predicted by their model, was of one or two orders of magnitude higher than the scanning speed. That means fluid particle would recirculate several times before it was solidified. This can account for the highly disperse and uniform solute redistribution within the molten region.

In the melting bath, the liquid circulation was induced by Marangoni flows and hydrodynamic motion, which was caused by pressure gradients [13]. In turn, Marangoni flows were determined by the temperature dependence of the surface-tension gradient $\sigma^{\prime}(T)$. A surface-tension gradient with consequent fluid flow could be imposed on the surface of a fluid in at least two situations [3]: (1) temperature gradient along the surface or (2) chemical composition gradient along the surface. In addition, the magnitude of the force generated by surface gradients could be large and can, therefore, dominate other forces such as convection from buoyancy effects. If a surface-tension gradient exists on the surface of a liquid, then fluid would be drawn along the surface from the region of lower surface tension to the region of higher surface tension. For example, the presence of a low concentration of surface active impurities could substantially alter the temperature dependence of the surface tension by changing its sign. However, in the absence of significant concentrations of surface active impurities, the melt exhibits the normal negative surface tension temperature coefficient for pure metals.

The effects of tensioactive elements (such as sulfur, selenium, and oxygen) on the shape of melted zone vary and depend on the temperature coefficient of surface tension. Some of them induce a deep melted zone and others a large but shallow one [14]. Walsh and Savage [15], in a survey about the effect of the minor elements in the case of CN7M, an iron-based alloy, justified the LMZ shape by the effect of the stable chemical compounds formed on the surface with iron or with other elements existing in the base material. Also, surface rippling during laser surface melting was attributed to surface-tension gradients [16]. Unfortunately, no data was available on the temperature dependence of the surface tension for most stainless steels. In many studies, the surface tension behavior was neglected or assumed to be that of pure metal.
The main focus of this work was to calculate temperature and velocity field in melted metallic material by a pulsed laser beam. Therefore, a numerical model was developed to solve a transient heat transfer problem, for which variations of its thermophysical properties are well known. This analysis improved our understanding of the effects of the irradiation conditions on the size of the melted zone during irradiation. Finally, the analyses of the surface profile of the melted zone with a non-contact method, called laser triangulation, are discussed. Experimental and numerical results are obtained and presented.

\section{Modeling of melting process}

\subsection{Laser beam function}

A LASMA 1054 Nd-YAG laser delivering output energy of 1-60 J at $0.3-20 \mathrm{~ms}$ pulses was used to irradiate the workpiece $\left(20 \times 20 \times 5 \mathrm{~mm}^{3}\right)$. The laser wavelength was $1.046 \mu \mathrm{m}$, the maximum transmitted power was $300 \mathrm{~W}$, and the frequency of pulses was in the range from 1 to $600 \mathrm{~Hz}$. Argon shielding $(15 \mathrm{l} / \mathrm{mn})$ was used to avoid oxidization of the material.

Knowledge of the spatial energy and the duration and the frequency of pulse generation of the laser were necessary to adequately model the system. The profile of the laser beam depended on the optics of the system [17] and could be oblong [18], circular, elliptical, or more often a combination of Gaussians $[19,20]$.

In this survey, the focal distance of the optical system was $140 \mathrm{~mm}$. Beam analysis by imagery software was used to determine the intensity profiles. For most part, the shape of the laser beam could be well approximated by a Gaussian profile (radius of the laser beam $r_{b}$ ). Therefore, we assumed in our model that the energy distribution was Gaussian. As a result, the energy flux density absorbed on the top surface $(z=0)$ is given as

$\left.Q_{\text {laser }}(t, x, z)=\delta \frac{E}{\tau} \frac{1}{\pi r_{b}^{2}} \exp -\left(\frac{x-\left(x_{0}+v t\right)}{r_{b}}\right)^{2}\right)$

where, $\delta$ is the absorption coefficient temperature dependent: $2 \times 10^{-8} T^{2}-8 \times 10^{-5} T+0.3407$.

\subsection{Material}

The interaction between the material and the laser beam is sensitive to the material composition and the nature of the laser 
Table 1

Experimental condition of multi-pulse laser irradiations. Operative and relevant parameters.

\begin{tabular}{|c|c|c|c|c|c|c|c|c|}
\hline \multirow[t]{2}{*}{ Samples } & \multicolumn{4}{|c|}{ Operative parameters } & \multicolumn{4}{|c|}{ Relevant parameters } \\
\hline & $E(J)$ & $\tau(\mathbf{s})$ & $\boldsymbol{f}(\mathbf{H z})$ & $v(\mathbf{m m} / \mathbf{s})$ & $P(\mathbf{w})$ & $D\left(\mathrm{~J} / \mathrm{mm}^{2}\right)$ & $\boldsymbol{R}$ & $\boldsymbol{B}$ \\
\hline M1 & 6.28 & 0.0126 & 7.962 & 1.67 & 500 & 50 & \multirow{5}{*}{0.5} & \multirow{8}{*}{0.1} \\
\hline M2 & 6.28 & 0.0063 & 15.924 & 3.35 & 1000 & 50 & & \\
\hline M3 & 6.28 & 0.0042 & 23.885 & 5.02 & 1500 & 50 & & \\
\hline M4 & 12.56 & 0.0084 & 11.943 & 2.51 & 1500 & 100 & & \\
\hline M5 & 6.28 & 0.0126 & 7.962 & 2.58 & 500 & 50 & & \\
\hline M6 & 6.28 & 0.0063 & 15.924 & 5.16 & 1000 & 50 & \multirow{3}{*}{0.25} & \\
\hline M7 & 6.28 & 0.0042 & 23.885 & 7.74 & 1500 & 50 & & \\
\hline M8 & 12.56 & 0.0084 & 11.943 & 3.87 & 1500 & 100 & & \\
\hline
\end{tabular}

beam. In this study, the material was considered pure iron in spite of the presence of some trace elements (typical analysis: $\mathrm{Mn}<800, \mathrm{C}<200, \mathrm{P}<200, \mathrm{~S}<150 \mathrm{ppm}$ ). In view of the foregoing, effects of the impurities were neglected. Thermophysical properties of iron (thermal conductivity, thermal capacity, viscosity, and density) and the phase transformations that occur in the material are well known $[21,22]$ (Table 1 ). The absorption coefficient, $\delta$ was taken to be temperature dependent [23].

\section{Modeling description}

\subsection{Governing equations}

A laser melting process is characterized by a small melt-pool size and a very short process. Due to these characteristics, measurement of important parameters, such as temperature and velocity fields, during laser welding are a big challenge. These parameters are important as they determine the geometry, composition, structure and resulting properties of the treated materials.

In this study, a Cartesian geometry was used, the $x-y$ plane for the surface of the workpiece and the $z$ axis for the depth. The laser beam moved at a constant velocity $v$, and the latent heat due to solidification and Boussinesq approximation were considered. The governing equations were the coupled mass, momentum, and energy conservation equations. These equations are given as (Eqs. (2)-(6))

$$
\text { Energy }
$$

$\rho C_{p} \frac{\partial H}{\partial t}+\rho C_{p} U \frac{\partial H}{\partial x}+\rho C_{p} W \frac{\partial H}{\partial z}=\frac{\partial}{\partial x}\left(k \frac{\partial H}{\partial x}\right)+\frac{\partial}{\partial z}\left(k \frac{\partial H}{\partial z}\right)$

In the energy equation, the enthalpy was defined as

$H=\int_{T_{0}}^{T} C_{p} d T+L_{m} F(T)$

\section{Continuity}

$\frac{\partial \rho}{\partial t}+\frac{\partial}{\partial x}(\rho U)+\frac{\partial}{\partial z}(\rho W)=0$

$U$ and $W$ are the $i$ and $z$ components of velocity $V(\mathrm{~m} / \mathrm{s})$. $x$ momentum

$\rho\left\lfloor\frac{\partial U}{\partial t}+\operatorname{Vgrad} U\right\rfloor=\frac{-\partial P}{\partial x}+\operatorname{div}[\mu \operatorname{grad} U]$

$z$ momentum

$\rho\left\lfloor\frac{\partial W}{\partial t}+\operatorname{Vgrad} W\right\rfloor=\frac{-\partial P}{\partial z}+\operatorname{div}[\mu \operatorname{grad} W]+\rho \beta g\left(T-T_{r e f}\right)$

where $k, c p, \rho$, and $\mu$ are the parameters for the thermophysical properties that were temperature dependent.

\subsection{Boundary conditions}

On the free surfaces, the boundary conditions are given as following:

- Thermal

In many researches, heat source was included in energy conservation equation [24]. However, in this study the heat source is positioned on the top surface

$$
\begin{cases}H=0 & \text { at } \quad t=0 \\ -k \frac{\partial H}{\partial z}=-h_{f} H+Q_{\text {laser }} & \text { at } \quad z=0 \\ -k \frac{\partial H}{\partial x}=-h_{\text {lib }} H & \text { at } \quad x=0, L \\ H=0 & \text { at } \quad z=Z\end{cases}
$$

\section{- Hydraulic}

At the melted bath surface, the surface tension variation with temperature must be balanced by the fluid shear stress since the surface must be continuous. Therefore, the shear stress at the surface is equal to the surface-tension gradient. At the free surface, the shear stress due to Marangoni effects or the surface tension-driven flow was included as a boundary condition for the momentum equation (Eq. (8)) [25].

In common with other works in the field, we made the following assumptions:

1. In mushy zone, the fluid flow was proportional to the liquid fraction.

2. The surface of the melt pool was assumed to be flat to simplify the surface boundary condition.

3. Surface rippling was not considered.

$$
\left\{\begin{array}{lll}
U, W=0 & \text { at } & t=0 \\
-\mu \frac{\partial U}{\partial z}=\sigma^{\prime} \frac{\partial T}{\partial x} & \text { at } & z=0 \text { and } T \geq T_{m} \\
W=0 & \text { at } & z=0 \text { and } \forall T \\
U, W=0 & \text { at } & x=0, L \text { and } z=Z
\end{array}\right.
$$

\section{Numerical resolution}

\subsection{Numerical scheme and solution}

The finite-difference method was used to solve Eqs. (2)-(8). The next step consisted of the discretization of space and time variables. The implicit finite difference scheme built a pentadiagonal 2D matrix. The UpWind scheme was employed to evaluate the combined convection and conduction heat transfer. This arrangement, which enabled the handling of the pressure linkages through the continuity equation, is known as the Semi-Implicit Method for Pressure-Linked Equations (SIMPLE) algorithm [26]. On the other hand, the solution of linear systems obtained from the discretized transfer equations was computed by the GaussSeidel method. In this calculation, it is necessary to use the under relaxation parameters $(=0.9)$ for velocities and the enthalpy to avoid numerical instabilities [27].

It is important to point out the solid-liquid interface is not known a priori. It is part of the problem to be solved. To start the solution, the pure conduction equation has to be solved until a certain molten pool region formed so that the momentum equation can be applied. The final discretized equation took the following form:

$a_{P} H_{P}=a_{E} H_{E}+a_{W} H_{W}+a_{N} H_{N}+a_{S} H_{S}+b$

where subscripts $E, W, N$, and $S$ represent the neighbors of the given grid point ' $P$ '. The ' $a_{i}$ ' terms are coefficients dependent on the 
diffusion and convection. The parameter ' $b$ ' includes the terms associated with the evaluation of temperature at the previous time step.

\subsection{Grids}

The timescale, which was much shorter for laser spot and small melt pool size, required the use of fine grids and very small time steps. A finer grid spacing $(80 \times 63)$ was used near the interaction region between heat source and material to improve computation accuracy. The minimum grid spaces along the $x$ and $z$ directions were 50 and $5 \mu \mathrm{m}$, respectively, and the time step was $0.5 \mathrm{~ms}$.

\subsection{Simulation cases}

The irradiation conditions were dependent on the operative parameters: pulse energy, $E$; pulse duration, $\tau$; pulse frequency, $f$; and scanning speed along the $x$ axis of the laser beam, $v$. Two relevant parameters characterized each laser pulse: the surface density of deposited energy, $F$, and the pulse power, $P$. Two other parameters described the pulse succession: the time ratio of laser emission, $B$, and the superposition ratio of two areas successively irradiated, $R$ [6]. The data used for calculations are presented in Table 1. Relevant parameters are functions of operative parameters [28].

Fig. 1 is a schematic diagram showing the overall iterative procedure for the calculation of temperature and velocity fields during pulsed laser melting. All these details were implemented on a $\mathrm{C}$ program running on a standard PC to calculate the evolution of temperature, the molten depth and width.

Two series of tests were selected. The time ratio of laser emission, $B$, was maintained at 0.1 , while the domain of variation



Fig. 1. Problem solving flowchart. of the superposition ratio $R$ was 0.25 or 0.5 . The relevant parameters and operative parameters are tabulated in Table 1.

\section{Results and discussion}

The samples were irradiated by a short pulse LASMA 1054 Nd-YAG laser [28]. Each test was repeated three times. Fig. 2 shows a typical micrograph of workpiece surface melted by laser irradiation (case M3). Each iron sample was polished before laser irradiation to ensure the same initial surface state. SEM analysis of all samples did not reveal chemical compounds created during the laser treatment. These results attest to the efficiency of the shield gas. Also, the SEM inspections did not show any shortcomings or micro-cracks within the melted metal.

\subsection{Temperature field}

According to the diagram presented in Fig. 1, the temperature field in all points of the grid was calculated at every step. Fig. 3 shows the temperature evolution versus time for different points

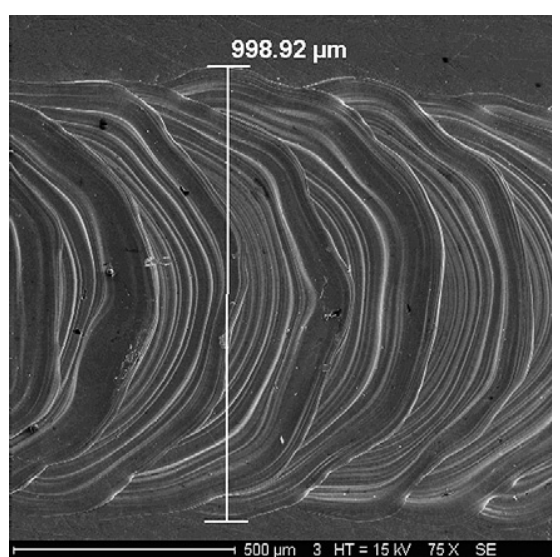

Fig. 2. Surface aspect of specimens after multi-pulse laser irradiation taken by SEM.

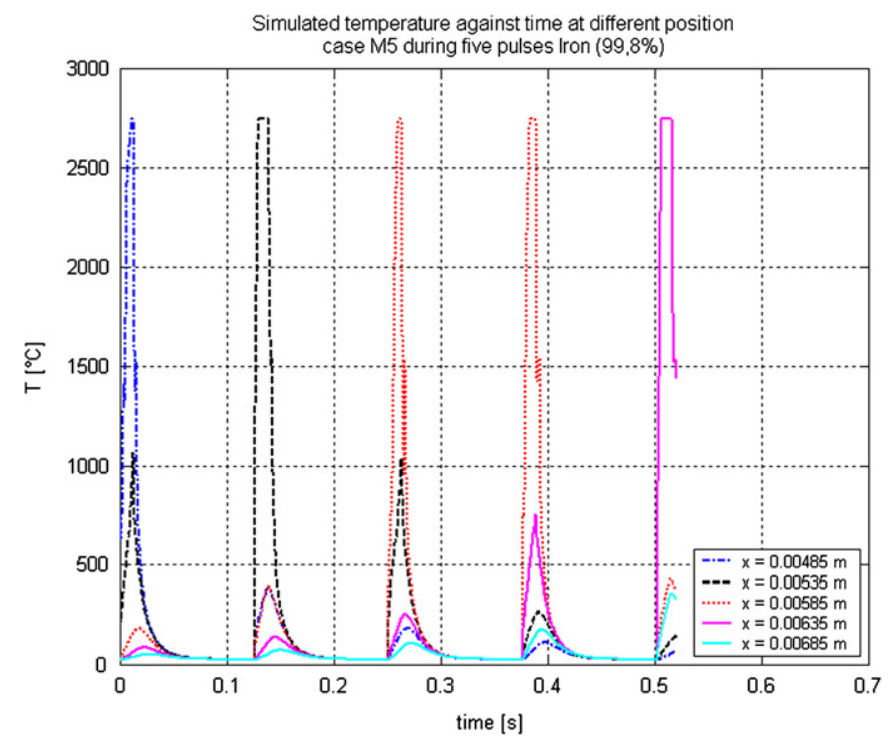

Fig. 3. Simulated temperature versus time at different points in the case M5 during five pulses. 
on the $x$ axis in case M5. The simulated treatment corresponds to five successive pulses. This result was achieved with a laser velocity of $2.582 \mathrm{~mm} / \mathrm{s}$ and pulse duration of $12.6 \mathrm{~ms}$.

\subsection{Velocity field}

The velocity field in the melted zone due to the Marangoni effects was calculated by using continuity and momentum equations. Since the temperature coefficient of the surface tension of pure iron is negative $\left(-0.23 \times 10^{-3} \mathrm{~N} / \mathrm{m} \mathrm{K}\right)$ as expected for a pure metal, the molten metal on the surface originated from the center of the melted pool and flowed to its periphery. Therefore, the pool shape became wider and shallower as compared to when the fluid flow was inward.

Fig. 4 shows the calculated velocity fields and the isotherms for case M4. The solid-liquid interface was approximated by steps and tracked by the melting point temperature. As could be seen in case $\mathrm{M} 4$, at $t=0.3575 \mathrm{~s}$, the maximum velocity in the melted bath was about $0.6254 \mathrm{~m} / \mathrm{s}$. In a similar survey, Semak et al. [29] showed that the velocity calculated in the melted bath, when iron was melted by a laser, varied between 1 and $3 \mathrm{~m} / \mathrm{s}$ for a surface density of energy of $0.5 \mathrm{MW} / \mathrm{cm}^{2}$, more than $10 \mathrm{~m} / \mathrm{s}$ for $1 \mathrm{MW} / \mathrm{cm}^{2}$, and between 20 and $30 \mathrm{~m} / \mathrm{s}$ for $5 \mathrm{MW} / \mathrm{cm}^{2}$.

\subsection{Surface profile}

In the present work, a laser triangulation sensor was used to study the surface profile. Sensor characteristics such as the spot diameter of $30 \mu \mathrm{m}$, the average response time of $4 \mathrm{~ms}$, and the wavelength of $670 \mathrm{~nm}$ were compatible for use in the measurement process.

This non-contact surface profilometer measured the heights of the surface ripples. These measurements were obtained after solidification, but they could be obtained while the treatment was in progress. The distance $\Delta d^{ \pm}$between the highest and the lowest point of the melted zone surface, for all samples is plotted in Fig. 5. The surfaces subjected to high surface density of energy, $F$, and high pulse power, $P\left(F \sim 100 \mathrm{~J} / \mathrm{mm}^{2}, P>1500 \mathrm{~W}\right)$, were those presenting more surface irregularities $\left(\Delta d^{ \pm}=0.1117 \mathrm{~mm}\right.$ and $\Delta d^{ \pm}=0.1241 \mathrm{~mm}$ in cases M7 and M8, respectively). Hence,

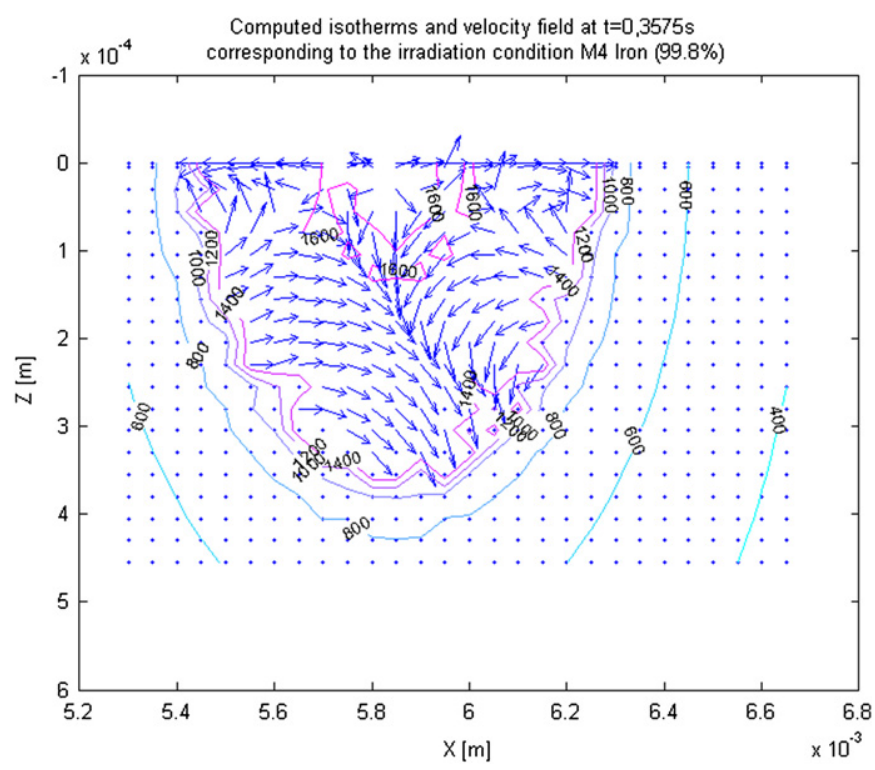

Fig. 4. Computed isotherms and velocity fields at $0.3575 \mathrm{~s}$ corresponding to the irradiation condition M4.

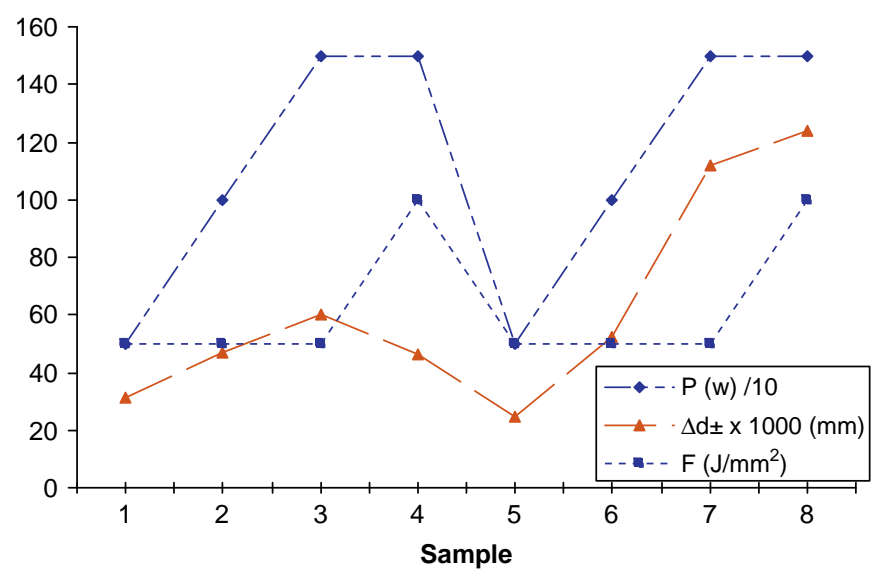

Fig. 5. Comparison between $\Delta d^{ \pm} \times 1000, F\left(\mathrm{~J} / \mathrm{mm}^{2}\right)$ and $P(\mathrm{~W}) / 10$.

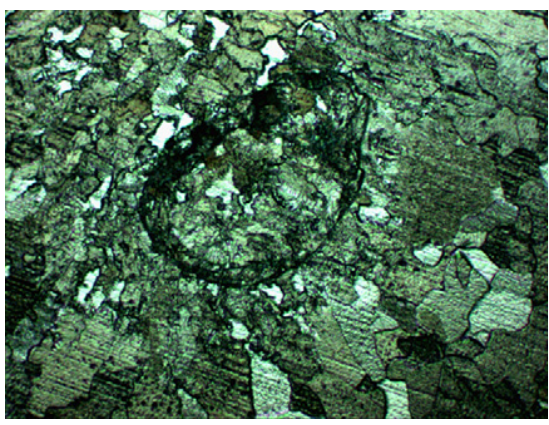

Fig. 6. Cavity shown into LMZ after solidification in case M8.

a correlation existed between these irregularities and the convection currents.

The works of Schaaf [7] showed that, for a laser spot light size of $14.6 \mathrm{~mm}^{2}$, increasing energy involved an increased thickness of the protuberance $\left(\Delta d^{+}\right)$and the depth of the gutter $\left(\Delta d^{-}\right)$.

Fig. 5 shows that for the samples M3, M6, M7, and M8, the surface of the melted zone was disrupted. The optical micrographs of those samples showed cavities confined in the LMZ (Fig. 6). These were keyhole formations during the treatment, resulting in a crater [30]. At the border of the crater, ridges of several $\mu \mathrm{m}$ in height were formed. In fact, when the surface density of energy is higher ( $>1000 \mathrm{~W}$ ), the liquid surface of the LMZ was distorted itself due to evaporation [31].

\subsection{Width and depth of the laser melted zone}

While comparing the curve representing the distance $\Delta d^{ \pm}$ between the highest and the lowest point of the melted zone surface (Fig. 5) with the curve representing the depth of the LMZ (Fig. 7), it is noted that the most unsettled surfaces of the LMZ correspond to the strongest penetrations of the melted zone. For example, in case M8 ( $\left.\Delta d^{ \pm} \sim 0.124 \mathrm{~mm}\right)$, the depth of the LMZ was $1002 \mu \mathrm{m}$.

Milewski and Sklar [32] showed that when a keyhole appeared, the laser beam was reflected multiple times, which led to an increase of the energy absorbed by the material. The depth of the melted zone was then drastically increased. This phenomenon, which was not taken into account in our model, explains the differences observed between the depths of the calculated and measurement of LMZ. This deviation is well correlated with surface profiles and keyhole phenomena. 

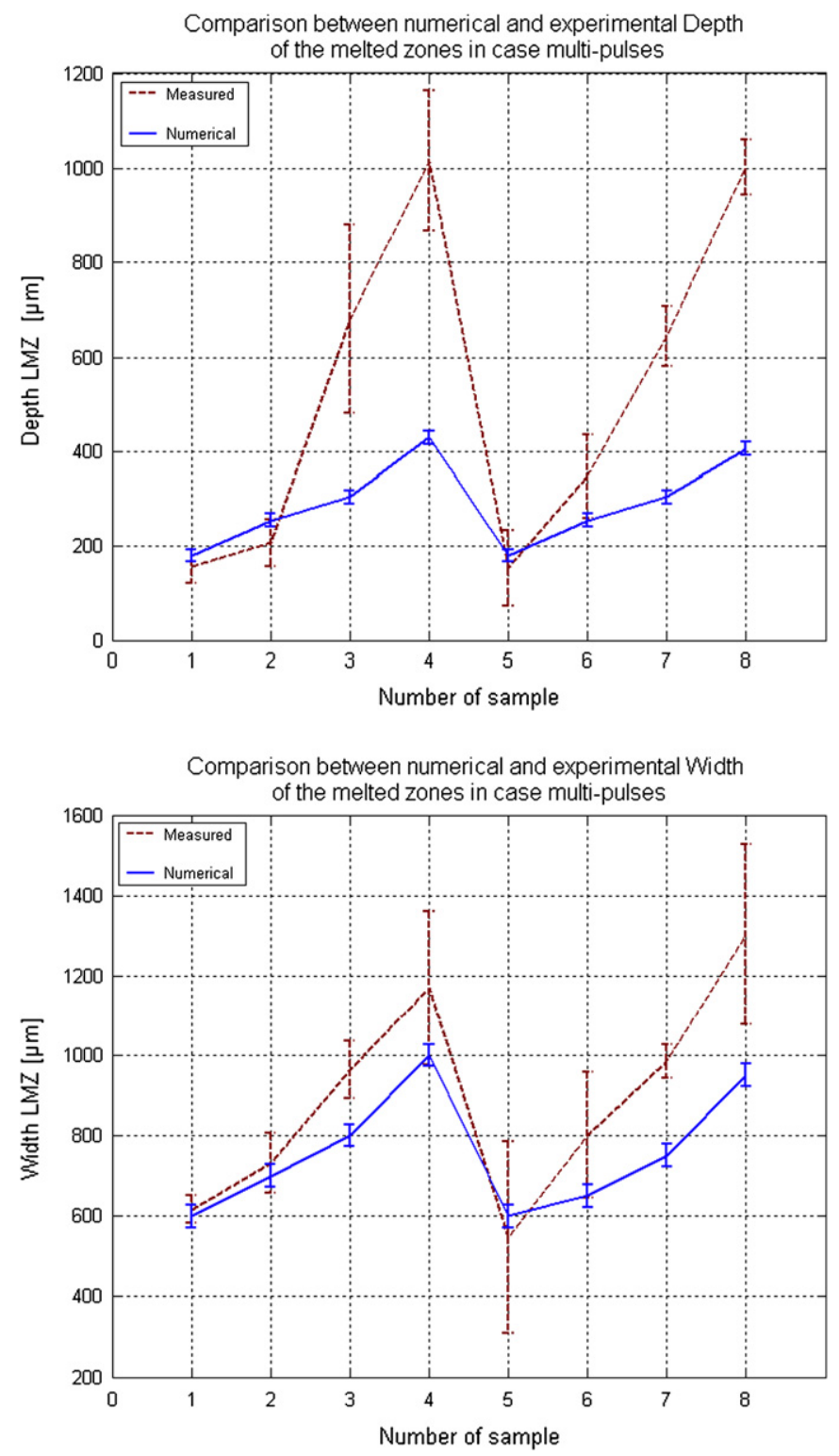

Fig. 7. Comparison between numerical and experimental depth and width of the melted zones.

\section{Criterion to avoid the keyhole effect}

The experimentally determined melt pool cross sections were compared to the corresponding computed values. Fig. 7 shows that for samples M3, M6, M7, and M8, experimental and calculated differences between the depths of the LMZ were significant. In these cases, $\Delta d^{ \pm}$was larger than $0.06 \mathrm{~mm}$. In the other cases, however, $\Delta d^{ \pm}$was between 0.024 and $0.06 \mathrm{~mm}$. These measurements allowed us to determine whether the keyhole effect was occurring. In particular, to prevent keyholing, $\Delta d^{ \pm}$must be kept approximately below $0.06 \mathrm{~mm}$. Accordingly, the calculated melt pool dimensions agreed well with the experimental results as long as cavities were not created.

In the other hand, when pulse power $P$ or surface density of deposited energy $F$ is high, the $\Delta d^{ \pm}$is important. However, when $P$ and $F$ are high the $\Delta d^{ \pm}$is higher. Therefore, $P$ and $F$ are two parameters that should be closely controlled in order to avoid keyholing. In these cases, if $P$ is greater than $1000 \mathrm{~W}$ and $F$ greater than $50 \mathrm{~J} / \mathrm{mm}^{2}$, the treated pieces have to be inspected to ensure adequate quality especially in manufactured products.

\section{Conclusion}

In this work, a modeling of the Nd-YAG laser surface melting process was developed to calculate temperature and velocity fields and melt pool shapes and sizes using a finite-difference method with the UpWind scheme. The numerical model solved the continuity, momentum conservation, and energy conservation equations. Variations of thermophysical properties, latent heat of fusion and solidification and Marangoni flow were taken into account. Several multi-pulse tests were carried out on a pure metal (iron 99.8\%). The effect of the operative parameters on the morphology of the melted zone and the convection movements were shown. The measured widths of the melted zones were in good agreement with the model predictions. However, the measured depths did not agree with the calculated ones when the surface density of energy and power of the pulse were too high due to evaporation. Analysis of surface profiles explained the differences between the numerical and measured results. Therefore, the use of the laser triangulation technique for quality control of surface treatment can be useful when other techniques are not applicable. A criterion was proposed to determine a keyhole effect with a surface analysis of the laser melted zone. These analyses can be used to optimize the laser power, the energy density, and the necessary time to realize high quality surface treatment.

\section{Acknowledgment}

This research is funded by the Institut de Recherche en Génie Civil et Mécanique, Université de Nantes-ECN in collaboration with the Institut Carnot de Bourgogne, UMR 5209 CNRS-Université de Bourgogne and Laboratoire Laser et Traitement des Matériaux, IUT du Creusot. The Loire Atlantique County Council and eduserveng.com are gratefully acknowledged for the financial support of this work.

\section{References}

[1] Chan C, Mazmuder J, Chen MM. A two-dimensional transient model for convection in laser melted pool. Metall Trans A 1984;15A:2175-84.

[2] Semak VV, Hopkins JA, Mccay MH, Mccay TD. Melt pool dynamics during laser welding. J Phys D: Appl Phys 1995;29:2443-50.

[3] Heiple CR, Roper JR. Mechanism for minor element effect on GTA fusion zone geometry. Suppl Weld J 1982:97-102.

[4] Lei YP, Murakawa H, Shi YW, Li XY. Numerical analysis of competitive influence of Marangoni flow and evaporation on heat surface temperature and molten pool shape in laser surface remelting. J Comput Mater Sci 2001;21:276-90.

[5] Huang C, Kou S. Partially melted zone in aluminium welds-liquation mechanism and directional solidification. Suppl Weld J 2000:113-20.

[6] Courant B, Hantzpergue JJ, Benayoun S, L'Huillier J-P. Melting and solidification processes in a moving graphite-covered titanium surface subjected to multi-pulse irradiation. J Phys 2001;34:1437-46.

[7] Schaaf P. Laser nitriding of metals. Progr Mater Sciences. 2002;47:1-161.

[8] Anjos MA, Vilar R, Li R, Ferreira MG, Steen WM, Watkins K. Fe-Cr-Ni-Mo-C alloys produced by laser surface alloying. J Surf Coat Technol 1995;70: 235-42.

[9] Sherclief HR, Ashby MF. The prediction of case depth in laser transformation hardening. J Metall Trans A 1991;22A:2459-65.

[10] Courant B, Hantzpergue JJ, Benayoun S. Surface treatment of titanium by laser irradiation to improve resistance to dray-sliding friction. Wear 1999;236:39-46.

[11] Kim MJ, Zhang. J. Finite element analysis of evaporative cutting with a moving high energy pulsed laser. Appl Math Modelling 2001;25:203-20.

[12] Kreutz EW, Pirch N. Laser de puissance et traitements des matériaux. Lausanne, Switzerland: Presses Polytechniques et Universitaires Romandes; 1991 pp. $535-55$

[13] Heiple CR, Roper JR. Effect of selenium on GTAW fusion zone geometry. Weld Res Suppl August 1981:143s-45s.

[14] Burgardt P, Heiple CR. Interaction between impurities and welding variables in determining GTA weld shape. Weld Res Suppl 1986:150s-155s. 
[15] Walsh DW, Savage WF. Technical note: autogenous GTA weldments-bead geometry variations due to minor elements. Welding research supplement: February 1985. p. 59s-62s.

[16] Antony TR, Cline HE. Surface rippling induced by surface-tension gradients during laser surface melting and alloying. J. Appl. Phys. September 1977;48: 3888-94.

[17] Avril L. Elaboration de revêtements sur acier inoxydable: simulation de la fusion par irradiation laser caractérisation structurale, mécanique et tribologique. Thèse doctorale. ENSAM d'Angers; December 2003.

[18] Steen PH, Ehrhard P, Schûssler A. Depth of melt-pool and Heat-Affected Zone in laser surface treatments. J. Metall Mater Trans A February 1994;25A: 427-35.

[19] Yilbas BS. Laser heating process and experimental validation. J. Heat Mass Transf 1997; 40:1131-43.

[20] Yilbas BS. A closed from solution for temperature rise inside solid substrate due to time exponentially varying pulse. Int. J. Heat Transf 2002;10:1993-2000.

[21] Techniques de l'ingénieur. MB2, M66, K420, M65, K430; 2004.

[22] Handbook of mathematical, scientific, and engineering formulas, tables, functions, graphs, transforms. Research and Education Association; 1992.

[23] Stern G. Absorption des rayonnements lasers $\mathrm{CO}_{2}$ et $\mathrm{Nd}-$ Yag en traitements de surface. Rév Fr de Méc 1995;1995-4:255-263.
[24] Dutto C, Fogarassy E, Mathiot D. Numerical and experimental analysis of pulsed excimer laser processing of silicon carbide. Appl Surf Sci J 2001;184: 362-6.

[25] Kim IS, Basu A. A mathematical model of heat transfer and fluid flow in the gas metal arc welding process. J Mater Process Technol 1998;77:17-24.

[26] Patankar SV. Numerical heat transfer and fluid flow. Washington, DC: Hemisphere; 1980.

[27] Özban AY. Improved convergence criteria for Jacobi and GaussSeidel iterations. Appl Math Comput 2004;152:693-700.

[28] Laazizi A. Contribution à l'étude du procédé de traitement des matériaux par faisceau laser pulse: confrontation simulation expérience. Thèse Université de Nantes. No. ED 00367231; 2006. p. 182.

[29] Semak VV, Damkroger B, Kempka DS. Temporal evaluation of the temperature field in the beam interaction zone during laser material processing. J Phys D: Appl Phys 1999;32:1819-25.

[30] Jouvard JM, Girard K, Perret O. Keyhole formation and power deposition in Nd:YAG laser spot welding. J Phys D: Appl Phys 2001;34:2894-901.

[31] Mackwood AP, Crafer RC. Thermal modelling of laser welding and related processes: a literature review. Opt Laser Technol 2005;37:99-115.

[32] Milewski J, Sklar E. Modelling and validation of multiple reflections for enhanced laser welding. Modelling Simul Mater Sci Eng 1996;4:305-22. 